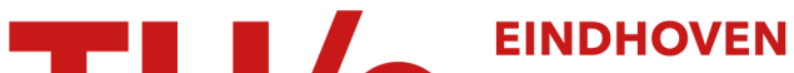 \\ UNIVERSITY OF \\ TECHNOLOGY
}

\section{Understanding moral responsibility in the design of trailers}

Citation for published version (APA):

Burg, van der, S., \& Gorp, van, A. (2005). Understanding moral responsibility in the design of trailers. Science and Engineering Ethics, 11(2), 235-256. https://doi.org/10.1007/s11948-005-0044-x

DOI:

10.1007/s11948-005-0044-x

Document status and date:

Published: 01/01/2005

\section{Document Version:}

Publisher's PDF, also known as Version of Record (includes final page, issue and volume numbers)

\section{Please check the document version of this publication:}

- A submitted manuscript is the version of the article upon submission and before peer-review. There can be important differences between the submitted version and the official published version of record. People interested in the research are advised to contact the author for the final version of the publication, or visit the $\mathrm{DOI}$ to the publisher's website.

- The final author version and the galley proof are versions of the publication after peer review.

- The final published version features the final layout of the paper including the volume, issue and page numbers.

Link to publication

\section{General rights}

Copyright and moral rights for the publications made accessible in the public portal are retained by the authors and/or other copyright owners and it is a condition of accessing publications that users recognise and abide by the legal requirements associated with these rights.

- Users may download and print one copy of any publication from the public portal for the purpose of private study or research.

- You may not further distribute the material or use it for any profit-making activity or commercial gain

- You may freely distribute the URL identifying the publication in the public portal.

If the publication is distributed under the terms of Article $25 \mathrm{fa}$ of the Dutch Copyright Act, indicated by the "Taverne" license above, please follow below link for the End User Agreement:

www.tue.nl/taverne

Take down policy

If you believe that this document breaches copyright please contact us at:

openaccess@tue.nl

providing details and we will investigate your claim. 


\title{
Understanding Moral Responsibility in the Design of Trailers
}

\author{
Simone van der Burg ${ }^{\delta}$ and Anke van Gorp ${ }^{\gamma}$ \\ ${ }^{\delta}$ Department of Technology Management, Eindhoven University of Technology \\ ${ }^{\gamma}$ Faculty of Technology, Policy and Management, Delft University of Technology
}

Keywords: engineering design, safety, practices, MacIntyre, moral responsibility

\begin{abstract}
This paper starts from the presupposition that moral codes often do not suffice to make agents understand their moral responsibility. We will illustrate this statement with a concrete example of engineers who design a truck's trailer and who do not think traffic safety is part of their responsibility. This opinion clashes with a common supposition that designers in fact should do all that is in their power to ensure safety in traffic. In our opinion this shows the need for a moral philosophy that helps engineers to interpret their responsibility and think more critically about it. For this purpose we will explore the moral philosophy of Alasdair MacIntyre, which is particularly interesting because he locates the beginning of moral thinking in the daily practice of a profession. This is consistent with the history of moral codes, for codes are also the product of moral reflection by professionals. We will use MacIntyre's philosophy to (1) explain what is wrong with the designers' understanding of their responsibility and (2) show a possible way to bring their reflection to a more selfcritical level. We will also inspect MacIntyre's proposal critically.
\end{abstract}

\section{Introduction}

In trailer design, traffic safety is not always systematically taken into account. In the Netherlands, as in many other countries, there is legislation to ensure the traffic safety of trailers, but often it is possible for engineers to do more than the rules require in order to prevent collisions or to reduce the amount and seriousness of injuries due to collisions. However, in the Netherlands as in many other European countries, engineers often do not take these measures. To the best of our knowledge, there is only one

Address for correspondence: Simone van der Burg, Subdepartment History, Philosophy and Technology Studies, Department of Technology Management, Eindhoven University of Technology, IPO 2.35, P.O. Box 513, 5600 MB Eindhoven, the Netherlands; email: s.v.d.burg@tm.tue.nl.

Anke van Gorp, Department of Philosophy, Faculty of Technology, Policy and Management, Delft University of Technology, P.O. Box 5015, 2600 GA Delft, the Netherlands, email: a.c.vangorp@tbm.tudelft.nl.

Paper received, 11 June 2004: revised, 21 December 2004: accepted, 21 December 2004.

1353-3452 C 2005 Opragen Publications, POB 54, Guildford GU1 2YF, UK. http://www.opragen.co.uk 
European trailer producer that has a trailer model in production, the Safeliner, that is designed to maximally protect people outside the trailer. ${ }^{1}$

In the Netherlands about $13 \%$ of the traffic collisions involve trucks. ${ }^{2}$ Usually these are serious collisions. The differences in mass, weight, stiffness and height make trucks dangerous for people on the road who use other modes of transportation. One of the problems in case of a collision between cars and trucks is the possibility that a car skids under a truck or trailer, often decapitating or otherwise fatally injuring the driver and passengers. Cars can pitch or skid under the truck and trailer from the sides but also from behind or front. Although in European countries like the Netherlands a bumper is required on a trailer so that it is more difficult for a car to pitch underneath it, crashes still occur on highways in which cars pitch under trucks and trailers. The trailer bumper cannot prevent this at speeds usual on highways. Another problem is that cyclists are sometimes overlooked. This regularly occurs in Dutch cities and villages: trucks turning right don't see a cyclist right next to them and the cyclist can fall under the wheels of the trailer. In order to prevent this, different societal groups, amongst others the Dutch traffic safety organisation (3VO) and a group of relatives of people who have died in these kinds of traffic collisions, have put pressure on the government to make an extra mirror - a so called blind spot mirror - obligatory for trucks, and to oblige trucks to install guards - two parallel beams - between the kingpin section and the wheels to keep cyclists from falling under the wheels. Since January 2003 the blind spot mirror is obligatory in the Netherlands. The European directive ordering blind spot mirrors will be in effect November 2006, requiring blind spot mirrors on trucks in all European Countries. ${ }^{3}$

However, it is possible to take more safety precautions than the law requires. Although the two parallel beams protect cyclists and pedestrians to a certain extent from getting under the wheels, full side covers would protect them better. This is called underrun protection, and is part of the crash compatibility. Also, it is possible to introduce sensors that alarm the driver when another vehicle is getting too close in an area where it cannot be seen. Both of these measures would help to prevent collisions which are usually very serious for non-truck drivers; for the truck will not deform when it crashes against a car or a pedestrian or cyclist because of the way in which it is constructed, but a car or bicycle will be seriously damaged and the driver, cyclist or pedestrian seriously injured or killed.

Crash compatibility - especially the underrun protection - is lately receiving more attention in reflections on traffic-safety measures and in European legislation. These measures will be legally obligatory in 2010 , but it is already possible to incorporate them in designs at this moment. The case-study that we present in this article shows a reason why this is not done: the engineers encountered in this case-study, do not feel responsible to develop and incorporate safety measures in their work beyond what is legally required. Engineers design a trailer that suits the requirements of their customer, and when underrun protection is not demanded by the customer or by legislation, they do not include it. They think that traffic safety is not their responsibility, but the responsibility of customers - the trailer producers - and of governments and drivers. But are they right to see it in this way? 
In general most people would say that they are not right. It is interesting to know how it is possible that this insight is not available to or acted upon by many European engineers. This is the question that is central to the first section of this paper: there we will ask how it is possible that engineers continue not to feel responsible for traffic safety, while it is in their power to take measures to reduce the numbers of traffic casualties. To explain this we will look at a concrete example of a design process for a lightweight trailer in the Netherlands. With the help of this example, we want to show that engineers in this project understand their responsibility only in the light of their role in the practice, and that this understanding steers their decisions, as well as their interpretation of the moral codes. The role of the codes interests us most. These codes are created by professional groups or companies in order to challenge the habitual interpretation of responsibility that is given in concrete practices. But it appears that they often fail to fulfil this critical role.

In the second section we will go one step further. There we will focus on an answer to the normative question concerning how these codes should be interpreted morally. We chose the philosophy of the Irish-American philosopher Alasdair MacIntyre because we think his approach is particularly interesting for an ethic of engineering. Unlike most other philosophers, who give morality a basis which is independent of social life and valid for all rational human individuals, MacIntyre claims that moral reflection typically starts in concrete social practices. He accepts that morality is learned, continued and changed within a social group, like colleagues who work together on a daily basis. But he also makes a clear distinction between a professional and a moral reflection, which we consider very important to the example we are treating. We think it offers a very useful starting point to think about a moral guideline that steers reflections about moral codes.

In this article we want to show that the basic building blocks of MacIntyre's moral philosophy connect closely to the way in which professionals already tend to think about issues. They also go together well with the history of moral codes. Moral codes are usually the product of a collective effort of people to make their work more moral: they are created by professional groups or by companies. We think MacIntyre's moral philosophy is able to provide a critical way to think about these codes, while respecting the origin of the effort of creating them in a concrete context.

In this article we will deliberately speak about 'practices', not about 'professions'. We are aware that there is an ongoing debate about what constitutes a profession and whether engineering can be regarded as a profession (see for example Davis ${ }^{4}$ and Didier $^{5}$ ). We want to avoid this discussion here, because in the Dutch situation this would raise several problems. In the Netherlands 'engineer' is a very general title which does not connect to any specific profession: everyone who has acquired a bachelor or master's degree in an engineering science is an engineer. There is also no licensing system for professionals. There are some professional societies which involve engineers, but it is possible to become a member of some of them without being an engineer by education but by doing certain work, for example the society for constructing in steel. ${ }^{6}$ In these societies 'being a professional' means that you practice it. Because the question regarding whether trailer design in the Netherlands belongs to 
a profession would demand extensive discussion which distracts from the general argument of the article - for here we use the case study of trailer design only as an example - we prefer to speak about 'practice' and leave aside the question of whether this counts as a profession.

We will discuss the basic structure of MacIntyre's approach, which is presented most clearly in his most famous book After Virtue. ${ }^{7}$ The first building blocks of his philosophy are introduced in the first explanatory section, for they help to understand what happens in the concrete case. This is important, for MacIntyre's view of what happens in moral life, is also the starting point for his perspective on critical moral reflection which will be explained in the second section. We will explore the possibilities that his moral philosophy offers to think critically about the way in which the engineers in the case study understand their responsibility, while at the same time staying very close to the concrete practice of their work.

\section{How do engineers understand their responsibility for safety?}

In this section we will focus on an example of a design process of a trailer, and explain how engineers evaluate their decisions about safety. One of the authors of this article observed such a process which aimed at the design of a lightweight trailer. Designing a trailer has different stages and the observation focused on the first stage which consists of a 'feasibility study' which tries to find an answer to the question: is it possible and economically feasible to design a lightweight trailer? In order to answer it, engineers create the possible layout of the trailer (a kind of preliminary design), and make an estimate of the costs of the material that they could use to make it. After this study they make a report, and on the basis of that, the customer will decide whether to go on with the project or not. In reality this phase in the design process lasted six months. The author that obtained the data for this case-study has observed and registered design meetings and held interviews with the engineers and customer. ${ }^{8}$ The observation period lasted from March 2003 to August 2003. During that period ten design meetings between the project engineers were held and three meetings with the project engineers and the customer; all these meetings were observed. The observation period ended with a presentation of the results and a discussion about it among the engineers.

Here we want to focus especially on the types of evaluations that engineers make before they decide on their actions, not on the technical issues. But in order to understand these evaluations, it is useful to introduce some of the terms that Alasdair MacIntyre uses in order to describe the ingredients of moral life. First of all, we need the term 'social practice', which plays a very central role in the way Macintyre views daily moral life. 'Practice', however, is a very complex term. It refers to a large variety of human interactions that can be distinguished from each other with the help of the goal that they aim to realise. Examples of social practices are games like chess or football, social roles like motherhood, friendship, marital partners, and professions such as journalism, chemistry or the design of trailers. In chapter fourteen of After Virtue MacIntyre introduces the term with a proper definition: 
'By 'practice' I am going to mean any coherent and complex form of socially established cooperative human activity through which goods internal to that form of activity are realised in the course of trying to achieve those standards of excellence which are appropriate to, and partially definitive of, that form of activity, with the result that human powers to achieve excellence, and human conceptions of the ends and goods involved are systematically extended. ${ }^{, 7(p .187)}$

This definition is very complex and contains many terms that may seem vague and general at first glance; like 'socially established activity', 'goods' and 'standards of excellence'. Each of these terms used in this paragraph will be explained in relation to the context at hand.

First of all, it is important to understand the difference between a practice and an institution. A practice is a 'socially established activity' in the sense that the evaluative order that regulates it generates from the daily interactions of the participants. This acceptance and ascription of responsibilities is seldom articulated in words, but mostly expressed in the way the practitioners deal with each other. That is typical for an evaluative order in a practice. We think that the studied design process of a trailer can also best be seen as a practice, because many of the evaluative criteria with which the engineers, who participate in it, work are not 'settled' or 'agreed on' by all parties; they spring from the history of their interaction. We will try to show that their understanding of their responsibility is also rooted in the historical background of their interactions. These engineers have this in common with other practices like football, science or nursing which also have their own evaluative order, which is only partly made explicit in rules or codes but remains largely implicit.

Institutions differ from practices. Institutions may contain practices, for the practice of football may be embedded in the institution of a football club, scientific research takes place within a university and nursing is one of the practices in a hospital. Each of these institutions is concerned with the distribution of money, power and status. That is what institutions according to MacIntyre typically do: they contribute to the preservation of the practice, but they are not the same as practices. ${ }^{a}$ The design process of trailers is also embedded in an institution, for the engineers signed a working contract, which offers them a salary; and their relationship with their customer has also been formalized by a contract. The contract states what services and products the engineering company will offer, and what price the customer should pay in return. Therewith the relationship is institutionalised.

We think that the observed design process of a trailer can best be understood as a practice, because of the unspoken nature of many of the evaluations in it. But it is also an institutionalised practice, for it is also a location where money is earned and power is distributed. The engineers, for example, are paid to do their job which also creates a

a. MacIntyre writes: '[Institutions] are involved in acquiring money and other material goods; they are structured in terms of power and status, and they distribute money, power and status as rewards. Nor could they do otherwise if they are to sustain not only themselves, but also the practices of which they are the bearers. For no practices can survive for any length of time unsustained by institutions.' 7 (p.194) 
hierarchical relation with their manager. But the customer also pays the engineers to do a service, which gives him also a special status and power. Money, power and status thus play a role in the interactions between the participants in the practice.

In the observed practice of the design of a lightweight trailer, the participants are engaged in making something that they have never made before. They are therefore unable to completely follow pre-created and institutionalised rules of construction regarding this specific kind of trailer. At the engineering company which we will call LWD, ${ }^{b}$ for example, the engineers have designed other trailers before, but this project is significantly different because the customer demands a trailer with no roof which will be loaded with sand. The LWD engineers have no experience designing this specific type of trailer, which means that they cannot fall back on an explicit model which shows how the construction should be made, and how the result should be judged. In this sense, this design-process differs from other so-called 'normal' designprocesses that are governed by an already established framework of legislation, regulation, standards and codes. ${ }^{\mathrm{c}}$

The customer, a trailer producer, who hired LWD to make the design does have experience making trailers that are used for cargo like sand; it has also developed a special unloading system for this type of cargo. But the customer, which we will call FloX, ${ }^{\mathrm{b}}$ usually makes these trailers of aluminium or steel, and the company would now want to make a lightweight version made of composites. A lightweight trailer is an interesting product, because European regulation specifies maximum weight for loaded trailers: the maximum total weight means that a lightweight trailer can transport more sand. However, FloX has no experience making trailers of composites, and therefore it needs the help of the engineering company LWD that specialises in designs with composites and knows about the problems and opportunities that the use of these offer. LWD uses design rules, calculations and finite element modelling for designs made of composites, skills that FloX lacks. Trailer producers like FloX usually work on the basis of practical experience; if they judge a certain material thickness to be sufficient, then they sometimes decide to make the next series of trailers with a little less material.

FloX thus hires LWD because of its special expertise. But LWD engineers also lack some knowledge, for the engineers have never designed a trailer without a roof, while the people from FloX have built many. And the LWD engineers do not know the unloading system that Flox has developed. So LWD engineers cannot restrict themselves to just following the given models, standards and rules: they have to invent something new that the rules do not prescribe, and in order to be able to do that they also need the expertise of FloX.

b. In the research the names of the companies and engineers have been changed, to protect the privacy of the engineers and customer.

c. Van de Poel, I.R. and Van Gorp, A.C., "The need for ethical reflection in engineering design; the relevance of type of design and design hierarchy," to appear in Science, Technology and Human Values, in 2006. The framework is partly formed by institutes external to the practice, partly by people inside the practice. Legislation and some other regulation, for example, is formulated by the national or European government, standards and codes are formed by the professionals themselves, who are organised in professional societies or standardisation institutes. 
The observation focused especially on the role of two participants in the engineering practice, who carried out the feasibility study in cooperation with the customer and the customer's advisor. These two engineers have different roles. In this paper we will call the project-manager Liz. Liz organises the design process, she keeps contact with the customer, performs some calculations and makes the report. Liz cooperates with another engineer, whom we will call Hans. Hans performs the finite element model calculations. Both engineers have different responsibilities, but these do not refer to a hierarchical order in the company, for in other projects Liz and Hans might switch roles. During the six months that were studied, there were three meetings between the engineers and the director of FloX and his advisor. In addition to that, the engineers had meetings together, sometimes including a colleague for advise, and they kept contact by telephone with their customer.

In all of these meetings a lot of written and unwritten evaluations govern the dealings among the participants. The engineers and the producers obey social rules that are often not written down, but remain largely implicit in their mutual expectations and reactions. Besides this, LWD-engineers follow a common and systematic approach to making an engineering design that they consider 'self-evident', because they have inherited this approach from previous working experiences and a common background. This systematic approach to making a design governs the way in which they judge the design that they plan to make, and the feasibility study that leads to it. All of these evaluations together make up what the practitioners consider to be excellence in trailer design. They are the self-evident 'rules' by which the evaluative order of the practice consists. Here we will describe what this order involves, and explain how it steers the engineers' view of their responsibility and their interpretation of the moral codes.

The social relation among practitioners is firstly restrained by some formalized restrictions which are closely related to the institutionalised form that the practice has acquired. The relationship between LWD and FloX, for example, is regulated by a contract that demands certain actions and behaviour from the practitioners. This contract specifies what services and products the LWD engineers are expected to offer in return for payment by FloX. The contract also includes some statements on liability. The engineering company LWD is only liable in cases of severe neglect or fraud. Finally, the contract demands reliable conduct from the engineers towards their customers; that means, for example, that they keep the project a secret towards outsiders, especially to possible competitors on the market. These rules demand a certain conduct, so they are important for the practice; but they are also connected to the institution, for they establish power-relationships: if the rules in the contract are transgressed, FloX or LWD can use legal power to enforce them.

But next to these formal social rules, many informal expectations govern the daily interactions between the participants. These make up the social order of the practice. These involve many examples that are 'self evident' in almost any practice like greeting when one comes in or saying 'thank you' at the right moments. But there are also expectations that are specific to this practice at LWD, such as the habit of wearing casual clothes, or sitting on the same side of the table during meetings with the customer. This table setting is not the result of a prior arrangement, nor is it 
coincidence; but it does help to affirm that LWD engineers agree on the position that they bring forwards as a team, while in fact they have sometimes been very critical while discussing it among themselves. Furthermore, there are expectations that govern the communication. Liz and Hans expect each other to be very open about the problems they encounter in their work, but they do not communicate all of these problems to the customer. They consider some problems their own responsibility as engineers or not relevant to explain to the customer, but they never explicitly agreed on what kind of things to say and what to keep silent. So they follow a kind of unspoken order.

In fact, all of these informal expectations have never been made explicit: they just involve things the participants expect each other to do or refrain from doing. But they are nevertheless important: a person that they value as a good practitioner will always satisfy the formal rules in the contract, as well as the informal expectations.

Apart form the social rules, engineers respect an evaluative order that constitutes their view of an excellent structural design. The work of a good practitioner will have to satisfy this order. This evaluative order governs the list of requirements for the design, on which both FloX and LWD agree. This list is a written standard of evaluation for the product which is established in one of the first meetings between the engineers and the customer. This list includes among others requirements statements about strength, stiffness, weight, costs, safety, handling and aerodynamics. A strength requirement is, for example, that a trailer should be strong enough to withstand the normal loading in normal use during several years and it should also be able to withstand some exceptional stresses and strains with minor damage. A stiffness requirement is that the trailer should look reliable and feel reliable even when a heavy driver walks through an empty trailer. The stiffness and strength requirements together constitute the structural requirements for engineers.

But there are also unwritten evaluations at stake in the process of the formulation of these requirements, and in the way they are interpreted. Both engineers and customer, for example, presuppose that it is the customer who should decide what is, and what is not, included in this list of requirements. This is not something that is prearranged: it is an implicit expectation of all participants. Next to that, the way in which the structural requirements are interpreted depends very much on the background of the engineers and customer. This background is established by experiences and education, which is not the same for all of them.

In order to satisfy the structural requirements, for example, engineers make use of the common and systematic approach to making engineering designs. This approach includes, for example, calculation rules for strength and stiffness. Some strength calculations are done by hand, others, mostly stiffness calculations, are done using finite element modelling. This approach steers the way in which engineers deal with the list of structural requirements agreed on by the customer. But the approach is not discussed or agreed on by all participants. In the case that was studied, for example, LWD engineers did not discuss it with FloX because the employees of FloX are not engineers. The owner and manager of FloX has no engineering degree although he has acquired a lot of experience and practical knowledge in producing trailers. FloX is a 
small company that has employed technically skilled persons that can produce prototypes, but they do not have Bachelor's or Master's degrees in engineering, so they lack the knowledge to interpret the approach used by LWD. In other design processes when the customer is also an engineer, and is capable to understand the approach, the LWD engineers might discuss this with the customer. In the case observed, however, they only show the results and tell little about the way in which they got to these results.

The common and systematic approach for structural requirements demands that engineers who design with composites, for example, measure or calculate the strains in the constructions. This differs from a design in metals, where stresses are the dominant measure. This is one of the "rules" that every engineer designing in composites knows and uses. Furthermore, the strains within composites should not exceed a certain level; the allowable strain. What the allowable strains are depend on the kind of composite, the environment in which the construction is going to be used (mostly temperature, moisture, time, chemicals, sometimes the effects of fires are also accounted for) and the loading scenarios. Engineers may use different codes in which the allowable strains are identified. Lloyd's Register, for example, gives allowable strains for composites in boats. There is also a set of allowable strains formulated by the Dutch governmental organisation Rijkswaterstaat in cooperation with CUR (knowledge centre for civil engineering in the Netherlands) ${ }^{9}$ and LDW. These allowable strains differ in what they include in the calculation, and in the actually specified allowable strain. They incorporate different ideas about good design, for example; what environmental influences on the material should be taken into account, and what are sufficient safety factors, etc.

In some cases, regulation or the customer requires engineers to follow a certain allowable strain. But if this is not the case, engineers are free to choose between different allowable strains. In this case, the engineers may choose for themselves. Because Liz has more experience with the allowable strains formulated by Rijkswaterstaat CUR and some of her colleagues, she decides to use these allowable strains.

The list of requirements for the product may also include other requirements than the above mentioned structural requirements, for example requirements concerning aerodynamics and traffic safety. However, the common and systematic approach of the engineers does not include ideas and rules on how to deal with these other requirements. The common and systematic approach contains everything that engineers will always take into account, and that they consider as their responsibility. This approach functions as a kind of guarantee that the customer will get a decent product. But traffic safety is not part of this approach in this engineering company. So, that means that making a decent product does not oblige engineers to take care that their product makes collisions less likely to occur. The idea that traffic safety is a requirement that products have to satisfy is not something engineers consider to be their job.

The common and systematic approach thus also draws a line between what is included and excluded in the engineers' responsibility. According to the engineers, a 
good trailer design has structural integrity and is not too costly. Of course the design has to comply with existing (traffic safety) legislation. But if the legislation is satisfied, they think they have fulfilled their responsibilities. Being an excellent designer of trailers does not demand more than this: other features that may be considered important in the design are excluded from the common evaluative order.

Of course, it is possible to do more than the evaluative order requires. Sometimes customers in fact ask for more. In this case FloX wanted the sides of the trailer covered. FloX regarded this however as part of the image of the trailer not the construction of the trailer. Flox first wanted a good construction and then they would have someone design the appearance and image of the trailer. As FloX considered covering of the sides of the trailer and the installation of underrun protection as part of the image and not of the construction, they did not include these features in the assignment for the design of the construction. ${ }^{\mathrm{d}}$ The consequence of this is that FloX did not include the covers in the list of requirements, nor did Flox negotiate about them with the engineers. The traffic safety that these covers provide is therefore not introduced by FloX as a relevant and self-evident topic in the engineers' reflections on a safe construction of a trailer.

At this point we may conclude that there is in fact a very clear evaluative order at stake in the practice of these engineers who design trailers. And safety does play an important role in this evaluation, but the engineer's view of a 'safe trailer' is based solely on structural measures. Accordingly, they also think that an excellent designer of trailers - in addition to obeying the law - will only be responsible for fulfilling all structural requirements. This understanding of their responsibility for safety is rooted in the common background of these engineers. During their education, and during the daily practice of their job, this kind of evaluation has been the common ground for the reflection of the engineers, which remains unchallenged.

The engineers at LWD also share this background, which becomes clear when we look at quotes from interview with them. Hans, for example, said in a discussion: 'The customer decides what we have to do and to what we have to pay attention. The responsibility for traffic safety lies with FloX, the customer.' Furthermore, when asked who is responsible for safety on the road, Hans answered: 'If I have done my work well, then the driver is responsible for that.' Hans herewith affirms that he considers himself only responsible for the integrity of the construction, not for the prevention of collisions. As an argument for this view, both Liz and Hans indicate that they are not experts in traffic safety or crash compatibility, but in construction design; and they point out that the customers don't include traffic safety in their requirements, and might therefore not want to pay for the extra costs that traffic safety improvements imply. Above all, the driver of the truck should drive safely and try to prevent collisions. Finally, Liz also points towards the government's responsibility for road

d. Note that a lightweight trailer was intended and that adding covers onto a structural integer trailers adds material and weight that is not used to support loads. Usually in lightweight design engineers try to prevent the use of materials on places where they do not bear loads or where there is already enough material to support the loads. 
safety, when she says: 'In this case [of trailer design], we rely heavily on the government for traffic safety regulation. .....The initiative to change trailer design to enhance traffic safety is taken by government or organisations of trailer producers or freight transporters.' So, the engineers think road safety is the responsibility of the customer, the driver and the government, but not of the individual engineer, except insofar as this is required by the customer or the government.

Because the engineers have always perceived a safe trailer to be a structurally integral trailer, they have never thought about traffic safety measures. Nor have they investigated how much these safety measures would cost or asked whether the customer would want to pay for further research into the crash compatibility of the trailer. It is striking that when the results of the case-study were presented to LWD, the engineers showed that they have very limited knowledge of traffic-safety aspects of the product that they are designing. During this meeting the LWD engineers asked whether collisions with trucks and trailers happen regularly and whether lots of people die in these kinds of collisions. They also asked themselves whether the design of the construction they make influences traffic safety. After a discussion they agreed that in designing the construction of a trailer they might indeed influence traffic safety. This shows that LWD engineers consider themselves primarily as experts in the design of constructions with composites, and evaluate themselves only as such. For all other knowledge they rely on experience the customer has with the product.

The educational and experiential background that engineers share offers a good explanation of the lack of traffic safety requirements in the design of trucks and trailers. Apparently engineers just use the evaluations that they are used to making, to determine what is and what is not their responsibility. Moral codes are intended to help practitioners to think critically about the way in which they usually carry out their practice and about their responsibility towards society, ${ }^{\mathrm{e}}$ but very often they appear to fail to fulfil this role. ${ }^{f}$ Most codes tell engineers to hold paramount safety, health and welfare of the public, or something similar. ${ }^{\mathrm{g}}$ However, the code itself does not specify how the word 'safety' should be understood, that engineers are required to protect. So, engineers are free to interpret it as they want. In practice they will often interpret it in

e. This intention can be recognised, for example, in the way in which the code of ethics of IEEE (Institute of Electrical and Electronics Engineers) is introduced :'We, the members of the IEEE, in recognition of the importance of our technologies in affecting the quality of life throughout the world, and in accepting a personal obligation to our profession, its members and the communities we serve, do hereby commit ourselves to the highest ethical and professional conduct and agree..., 10

f. In the Netherlands engineers are not obliged to be registered or obliged to be member of a professional organisation, so the engineers are probably not a member of a professional organisations. Still codes of ethics for engineers are very interesting because they articulate what an engineer's responsibility is towards society.

g. See for example the model code of ethics from ABET (Accreditation Board for Engineering and Technology). ${ }^{11}$ Through the online ethics centre website other codes of ethics from amongst others IEEE (Institute of Electrical and Electronic Engineers), the NSPE (National Society of Professional Engineers), the Institution of Engineers Australia and the Information Processing Society of Japan can be accessed. ${ }^{12}$ Examples of company codes of ethics can be found at websites of for example BP, Dow, Whirpool corporation, Lockheed Martin. ${ }^{13}$ 
line with the common understanding that they already have of their work. That means in this case that the engineers will define safety as structural integrity, and accordingly, they will think that the code requires them to make sure that the structure of the design is solid in all reasonably foreseeable circumstances.

Structural requirements are indeed very important, but the word 'safe' could also be interpreted in another way. For the public, holding safety paramount means that engineers will also do all that is in their power to prevent traffic collisions from happening, or to keep the injury to a minimum in case of a collision. This points us towards a lack in the code: for an ethical code usually does not tell us what interpretation of the word 'safe' should be chosen, and thus allows engineers a lot of liberty to understand their responsibility as they like. In the daily practice of trailer design this will mean that the codes of ethics are merely interpreted in line with the common evaluative order of the practitioners.

Moral codes are usually very formal and abstract, and that is a problem if we want to use them as a guideline for moral thinking. They do not challenge the practitioner's common understanding of their profession enough. Practitioners tend to interpret them on the basis of their habitual evaluation. Therefore they fail to make a clear distinction between their professional and their moral responsibility. So, what is lacking is a moral philosophy which can provide a way to distinguish between the two, and therefore help their reflection to be more self-critical. In the next section we will explore the merit of Alasdair MacIntyre's moral philosophy to this end. With our choice of MacIntyre, we show respect for the way in which engineers already think about moral issues, for he thinks morality starts in practices. But we also want to show in what ways the reflection within practices may fail to be moral.

\section{MacIntyre's approach towards the moral responsibility of engineers}

In order to make a distinction between different types of evaluations that engineers make, it is useful to turn to MacIntyre. MacIntyre distinguishes sharply between different meanings of the word 'good' that participants in a practice may use. First of all, he distinguishes between 'internal goods' and 'external goods', which both do not

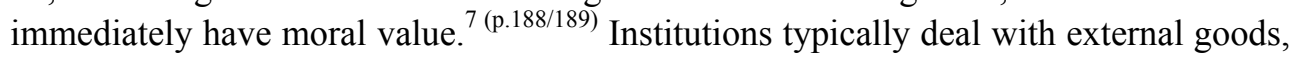
examples of which are money, power and status. 'External goods' are called 'external' because they are not specifically connected to one practice; we can acquire them in different practices. It is, for example, possible to earn money as an engineer, but also as a scientist, a football-player, or baker; and it is possible to acquire a certain status in any of these professions. Furthermore, in order to understand the value of external goods, no particular knowledge or experience in a practice is needed. The knowledge of the value of money is available, no matter in what practice one takes part. Finally, external goods are always an object of competition between people: when one person has more of it, others will have less.

'Internal goods', by contrast, are called 'internal' because they can only be identified, recognized and realized by people who participate in a practice. In order to 
understand these goods, it is important to remember that MacIntyre has a teleological view of the practice: according to him practitioners typically strive to achieve a goal in a practice, which is to become an 'excellent practitioner'. This goal -or telos- of the practice, and the knowledge and skills that are needed to realize it are examples of 'internal goods'. In the practice of the game of chess, for example, practitioners develop analytic skills, strategic imagination and competitive intensity, which are valued in the light of the goal of chess: winning. Without this goal these capacities would loose their value. Likewise, rhetorical or negotiation skills and the capacity to work in a team are important qualities in the practice of a democratic government. These qualities are valuable in connection to the goal of this practice; namely, acquiring votes and governing a region or country in a democratic way. ${ }^{\mathrm{h}}$ MacIntyre thinks that the achievement of these 'internal goods', unlike the competitive external goods, enriches the whole community of practitioners: although they are also the result of a competition to excel, they typically advance the whole community. ${ }^{\text {i }}$

In the practice of LWD engineers both these types of goods play an important role. The external goods are involved in evaluations that ascribe money or power to people, in exchange for services. The contract that the engineers make with their customer offers an example of these goods: in this contract it is specified what is earned in exchange for what services. Internal goods involve all evaluations that constitute how the engineers think their practice should be fulfilled. We have seen that an excellent practitioner, according to them, has all skills and knowledge in order to design a structurally reliable but not too costly trailer. This is also the kind of evaluation that they use in order to understand the moral responsibility of engineers. But MacIntyre would not agree with that: in his philosophy moral evaluations differ from internal goods. What is the difference?

In MacIntyre's philosophy the moral meaning of good is understood in the light of a more general telos: while something is judged internally good in connection to the goal of a practice, we can understand the moral meaning of 'good' in relation to the 'good life', which is the ultimate goal of life as a whole. So, his philosophy offers a way to distinguish between moral excellence and practical excellence. Both meanings of 'good' need to be understood in the context of a different telos. This also means that the internal and the moral meaning of 'good' require a different kind of reasoning. In order to defend something that is an internal good, it suffices to show how it realizes or advances the realization of the goal of the practice. But if one wants to argue for the moral value of an action or characteristic, one needs to show why it realizes or helps to achieve the good life.

h. MacIntyre describes the internal goods as follows: 'We call them internal (..) because they can only be identified and recognized by the experience of participating in the practice in question. Those who lack the relevant experience are incompetent thereby as judges of internal goods. ${ }^{7(p .188 / 189)}$

i. MacIntyre writes: 'External goods are therefore characteristically objects of competition in which there must be losers as well as winners. Internal goods are indeed the outcome of competition to excel, but it is characteristic of them that their achievement is a good for the whole community who participate in the practice. ${ }^{7}$ (p.190/191) 
MacIntyre's interpretations of the term 'good' help to understand what might be lacking in the decisions of the LWD engineers in the case-study. These engineers understand their responsibility as engineers solely in relation to the goal of the practice. They think it is their responsibility to design trailers that are structurally reliable and not too expensive, and therefore they choose not to include measures that help to assure traffic safety. Therewith they successfully discern their practical responsibility, but when we speak about moral responsibility we require something more. According to MacIntyre's moral philosophy, this 'something more' is a reflection on the good life. If we look at the case with the help of his distinction between meanings of 'good', we would have to conclude that the engineers' understanding of their responsibility is the object of moral criticism, because they fail to look at it in the light of the goal of life as a whole.

The obvious question that rises at this point is: what is the good life? MacIntyre's philosophy remains vague on this issue. He does not specify what the good life is, for he thinks that this is the object of a personal search. In After Virtue MacIntyre chooses the medieval term 'quest' to refer to this search. ${ }^{j}$ He does this for two reasons. First of all, because it is typical for a quest that it aims to understand a goal that is unclear at the beginning of the search. A quest differs, for example, from the search for oil or gold, where the object that is sought is clearly specified in advance; for in a quest the object is further specified during the process of the search. Another reason to call it a 'quest' is that in a 'quest' theory and practice are thoroughly intertwined. While the word 'research' has an academic meaning and could be understood solely in a theoretical way, a quest aims to acquire a theoretical as well as a practical understanding of the good life for the individual and for human beings in general.

In the process of the search, theory and practice are thoroughly intertwined, for MacIntyre thinks that the search for the good life always develops on the basis of the practices in which an agent takes part. The practice is able to offer the individual an initial view of the 'good life', which can serve as 'material' for reflection on the basis of which the quest may proceed. MacIntyre shows this in many quotes, such as the following in which he speaks about the practice of artistic painting:

'For what the artist discovers within the pursuit of excellence in portrait painting - and what is true of portrait painting is true of the practice of fine arts in general - is the good of a certain kind of life. That life may not constitute the whole of life for someone who is a painter by a very long way or it may at least

j. See 7(p. 218-219) for MacIntyre's view on the moral quest. MacIntyre here describes the moral research in contrast to the search of the miner and the geologist. In this paragraph these examples are copied. See also ${ }^{18(\text { pp.62-63) }}$ in which he gives his most clear definition of moral enquiry: 'The telos of moral enquiry (..) is excellence in the achievement not only of adequate theoretical understanding of the specifically human good, but also of the practical embodiment of that understanding in the life of the particular enquirer (..). Moral enquiry, as understood by Socrates, by Aquinas, and by those who took their place in the movement to Aquinas from Socrates, thus aspires to answer the question 'What is the good and the best, both for human beings in general and for this specific kind of human being in these particular circumstances here and now?' both theoretically and practically.' 
for a period, Gauguin-like, absorb him or her at the expense of almost everything else.' 7 (p.190)

The goal of the practice of painting gives painters a view of the good life, and they may think - for a while - that this is what it is. But according to MacIntyre one practice cannot offer a full account of the good life, because an agent most often participates in several practices at the same time, and the goals of these practices may conflict. These conflicts cannot be resolved on the level of practices alone: a view of the good life is needed which transcends practices, and is able to show what practice deserves priority at what times. Without such a view of the good life that transcends practices, it is impossible to choose among the practices in which one takes part.

MacIntyre therefore thinks that a practice offers but an initial view of the good life, with which the quest starts: this view will be questioned due to conflicts between practices that the agent will encounter in life. And as a result of that questioning the view of the good life will develop. So it is in the process of taking part in practices, and reflecting on the questions and conflict that one encounters in it, that a view of the good life acquires its shape. ${ }^{\mathrm{k}}$

It is not hard to imagine how such a quest could proceed. In the case study of the practice of trailer design we have seen that the engineers do not make a clear distinction between moral values and other types of values. What morality means simply gets shape in connection to the habitual evaluative order of their profession. But according to MacIntyre's view if we want to understand the moral value of their decisions, we have to ask if they continue to be satisfied with their decisions in view of the good life. This means that engineers - if they want to engage in a moral reflection can never restrict themselves to a line of reasoning on the basis of their profession alone. They will have to consider their lives as a whole.

It is very probable that the engineers also participate in several other practices: they are not only engineers, but they are also parents, friends or neighbors and road-users. The evaluative standards inherent to these practices may conflict with each other. As a mother, for example, an agent thinks it is self-evident that she should protect her children against the dangerous traffic, while as an engineer she thinks she should choose the most inexpensive trailer design which is structurally safe, but not safe in traffic. These goals conflict with each other. Engineers who are not parents encounter a comparable problem, for if they have friends they are also required to do all that is in their power to prevent their friends from getting hurt, and if they are drivers of cars, cyclists or pedestrians they very likely aim to get somewhere without getting hit by a truck and pitch under it. The goals of these practices also conflict with their choice as designers of trailers. Participation in these diverse practices invites the engineers to engage in a type of reflection that transcends their practice of trailer design, and shows

k. See ${ }^{7(p p .201-202)}$ where MacIntyre explains why morality can not be solely based on practices. His account does not separate clearly between his view on the virtues and his view on moral reflection. Both are treated at the same time, however I choose to separate both for reasons of clarity. 
that they have reason to try to do all that is in their power to prevent traffic collisions from happening.

This type of moral reflection is at once context-related and general. It is contextrelated because it is on the basis of questions that generate from concrete conflicts between practices that the moral quest starts, and is pushed forwards. The evaluative order of a practice, according to MacIntyre, can only offer a person an initial view of what the good life means; namely, becoming a good football player, friend, doctor, scientist or designer of trailers. But this cannot be a complete view. Usually the life of a human being is not restricted to one practice, and the confrontation of the different practical evaluative schemes will pose the agent serious questions. An evaluation on the basis of one of these practices can never give the agent a moral reason to act. In order to make a moral choice, the agent has to make a hierarchical order between the conflicting evaluative orders, change the requirements of one of them, or abolish some of the demands. ${ }^{1}$ Typical questions that the agent may ask in this situation are: how can I combine the different evaluative orders, which are important to me because they belong to my practices, into one coherent whole? What does the good life mean to someone who takes part in all kinds of different practices, as I do? ${ }^{7 \text { (p.201/202) }}$

This view helps to show what the LWD engineers should do in order to attain a proper understanding of their moral responsibility. They will be able to see what their moral responsibility is, if they inspect it in the light of a view on the good life as a whole. In order to do this, the engineers will have to look at all the evaluative orders that they obey in different practices, search for conflicts between them, and try to harmonize them. Any conflict between these orders poses a problem that the moral quest should try to solve. The evaluative order that results from the dialectic process of detecting conflicts, and harmonization of the conflict, shows what the good life means to these engineers. This view of the good life is rooted in their own lives.

This offers an interesting way to look at the case-study. However, we might ask whether we can expect that all engineers who work in the practice of trailer design will be prepared to engage in this type of reflection. Two worries can be articulated at this point. As has been shown in the examples above, MacIntyre's view on moral reflection remains firmly tied to the factual world: the concrete practices in which a person takes part determine the kind of questions that he or she confronts, and therewith influence the direction in which the moral quest proceeds. This dependence of the moral reflection on the factual world may be considered problematic. It is, for example, imaginable that one of the engineers does not take part in any other practice outside of the practice of trailer design. He or she returns home right after work, and lives in the forest -with no traffic around - like a hermit. Such a person will not encounter any conflict between the evaluative orders of his practices in his daily life,

1. This is the first feature of a 'quest'. In the following quote he states that he starts the quest with the questions that generate from the context of the agent: '(..) without some at least partly determinate conception of the final telos there could not be any beginning to a quest. Some conception of the good for man is required. Whence is such a conception to be drawn? Precisely from those questions which led us to attempt to transcend that limited conception of the virtues which is available in and through practices. 7 (p.219) 
for he or she only participates in one. As a consequence this person does not experience the need to rethink the standard of evaluation that is used in engineering practice. He or she will never be triggered to think critically about the goal of the practice of trailer design, and may conclude that there is nothing morally wrong with the decision not to take measures that make trailers safer in traffic.

A second worry is that an engineer who in fact does participate in different practices may be unaffected by the conflicts between the evaluative orders. In the current world in which people often make sharp distinctions between a private life and a professional life, it is easy to imagine that people may respect conflicting evaluative orders at work and at home, and think that this is unproblematic. A designer of trailers, for example, may think that it is natural in a free market system that persons and companies try to earn as much money as possible, and therefore approve of the decision not to include more traffic safety measures in the design, while she also defends the view that home should function as a safe haven where people should protect each other. The discrepancy between these two responsibilities does not motivate her to try to harmonize the two evaluative orders.

These worries immediately come to mind when one considers MacIntyre's view on morality. But the first worry does not seem to pose a realistic problem. It is of course imaginable that some people live a life in which they do not encounter any conflict between evaluative orders, and who therefore conclude that their evaluation as designers of trailers also has moral value. But in reality this situation will not often occur, for human beings are most often social beings who participate in several practices at the same time, and if they are not, they will at the very least be sensitive to stories about people who do and who encounter conflicts. In any case, none of the engineers in the case-study lives like a hermit.

The second worry is more troublesome. For even if persons recognize that the evaluative orders that govern the practices in which they take part conflict, it is possible that this does not motivate them to engage in a moral reflection on the good life. MacIntyre's answer to this problem is rooted in his moral psychology. As has been said, his account of the moral quest is not only an intellectual enterprise, but it is also practical. This means also that it goes together with a psychological development of emotions and desires within practices. In the process of trying to understand what the good life means in and outside practices, people also train their motivation to strive to achieve certain ends and avoid others. The development of the virtues is the psychological counterpart of the reflective strivings to realize the good life, and ensures according to MacIntyre that people will in fact experience conflicts between the practical standards of evaluation as problematic.

Virtues belong to the domain of the psychological development. Virtues are acquired human qualities that usually figure in descriptions of people's personality or behavior, but not in their deliberations about what they should do. A courageous person, for example, typically does not choose an action because it is courageous: she chooses it because to her it seems the action that the situation requires. An observer who describes the act or the agent might use the word 'courageous', but while it may 
be true that courage drove her to this action; 'courage' does not figure in the reasons why she chose it. ${ }^{\mathrm{m}}$

This does not mean, of course, that virtues can never be part of a moral deliberation. A shy person might deliberately put herself in threatening situations, because she thinks that will help her to acquire the virtue. In this case she acts because of the virtue, thus the virtue is part of the deliberation that lead her to the action. Also, people who know they possess certain virtues, might consciously restrict their tendency to act in accordance with them. A humorous person might, for example, force himself to think of sad, dull things in order to prevent himself from joking at a funeral, which he thinks will be inappropriate. Here virtues are also part of the reason why he acts as he does. But usually we regard virtues as psychological characteristics that will give a person a tendency to act in a certain way, or think about certain things, but which are themselves absent in their thoughts. They are therefore important if we want to understand why persons are motivated to do or refrain from doing certain things.

In MacIntyre's work, the development of the virtues is closely connected to the moral quest. In fact, in After Virtue MacIntyre mixes the presentation of his view on the moral quest completely with his account of the way in which persons acquire virtues. Both need the practices as a first starting point. Practices offer the basis from which the moral quest departs, but it is also the context in which persons first acquire virtues. MacIntyre thinks that it is in the process of trying to excel in a practice that these virtues play a role:

'A virtue is an acquired human quality the possession and exercise of which tends to enable us to achieve those goods which are internal to practices and the lack of which effectively prevents us from achieving any such goods. ${ }^{, 7}$ (p.191)

While a person strives to realize the internal goods, he or she will also develop moral characteristics. This does not necessarily mean that people who excel in the practice are also moral people, for it may be that their successes depend on the virtues of others. " But it is very likely that in the process of trying to master the skills and knowledge of practices like engineering, medicine, politics or farming people will also learn and develop characteristics that will drive them towards a moral quest. This is partly necessary because virtues are needed in order to be able to function in a practice. According to MacIntyre, people who want to be practitioners have to be at least to a minimal extent just, honest and courageous. Without these virtues they cannot function

m. Bernard Williams clarifies this in a very clear way in Ethics and the limits of philosophy. ${ }^{17}$ Here he states that the virtues mostly figure in an observer's description of an action or person, but not in the reflection of persons themselves which leads to their actions. He rightly states that the virtue of kindness typically does not figure in the kind person's deliberations about what to do: 'The benevolent or kind-hearted person does benevolent things, but does them under other descriptions, such as "she needs it", "it will cheer him up", it will stop the pain". The description of the virtue is not itself the description that appears in the consideration. ${ }^{17}$

n. MacIntyre does not claim that people who excel in a practice are also morally good. Although the learning process of internal goods and moral goods are intertwined, he continues to separate both from each other. "It is no part of my thesis that great violinists cannot be vicious or great chessplayers mean spirited. Where the virtues are required, the vices also may flourish.,7 (p.193) 
in a social group, and they are unable to engage in the learning process that precedes the excellent exercise of the practice. Justice, for example, is needed in order to be able to see who deserves praise and who should be blamed in the practice, and to understand one's place in the group; Honesty is a prerequisite for any dealings in a social environment, and it is needed in the learning process if one wants to have an insight into the quality of one's own work and accept criticism; Courage is also indispensable in the social world as well as the learning process, for one needs a drive to continue even when one is temporarily set back by criticism or blame. ${ }^{\circ}$

Virtues explain a tendency in the actions of a person; a drive to act in a certain way, or to refrain from acting. They are the result of a social training of the desires, which were originally aimed at a wild diversity of ends. In the first phases of a human life this training is 'undeliberative'. In After Virtue MacIntyre does not speak much about these earlier phases, but in Three Rival Versions of Moral Enquiry, ${ }^{18}$ he calls them 'pre-rational' for in order to become the kind of person who is able to concentrate and learn the relevant knowledge and skills from fellow practitioners, desires have to be properly directed, and habits cultivated. ${ }^{\mathrm{p}}$ This learning process is at first pre-rational, for parents do not always tell their children why they should shut up, finish what they started, be nice, polite, truthful and listen to what they are told. Virtues like temperance, persistence, courage, honesty, respect and justice are not rationally reflected on by the agent, and accepted; they have already become part of their character before they are able to judge their value, but they shape what people have a tendency to do or refrain from doing.

In MacIntyre's philosophy it is the virtues that ensure that persons will be motivated to try to harmonize the evaluative standards of the practices in which they take part. Virtues are characteristics of a person's character, and -as such - they are not only important within practices, but continue to be part of a person for the rest of his or her life. It is not possible to be honest in one practice, and lack that virtue in another one. A person either has or lacks a virtue whatever practice he or she is undertaking. This suggests that persons will have a tendency to do the same kinds of actions in whatever practice they take part.

In After Virtue a defense for this view can be found in chapter fifteen, where MacIntyre also introduces the moral quest. Here his view on the quest is preceded by a defense of a view of the self which is a unity. It is a very rich chapter, but one of the things that is at stake here, is the worry about the motivation to do the quest. Persons, according to MacIntyre, will do this kind of quest, because they are people who

o. '(..) we have to accept as necessary components of any practice with internal goods and standards of excellence the virtues of justice, courage and honesty.' 7 (p.191)

p. MacIntyre here calls this the 'paradox of the Meno' which he considers to be part of any learning experience. The paradox which originates from Plato's Meno is as follows: '(..) only insofar as we have already arrived at certain conclusions are we able to become the sort of person able to engage in such enquiry so as to reach sound conclusions.' ${ }^{18 ~(p .63 ; ~ p p .61-64 ; ~ p p .81-84) ~ P l a t o ~ s o l v e s ~ t h i s ~}$ mystery by drawing attention to a certain potentiality we have within ourselves for moving towards the relevant conclusions. MacIntyre, however, thinks it is because we first acquired capacities under the authority of a teacher in a practice. 
identify themselves with the practices in which they take part. And they cannot identify themselves with two practices that contain conflicting evaluations. Such conflicts will be problematic to them. It is as if they ask them to be two kinds of persons. If they want to avoid a severe depression or identity crisis, they will try and search for a harmonization between the evaluations of the practices in which they take part. Without this harmony they will feel fragmented. ${ }^{\mathrm{q}}$

This view of the self is integrated into all aspects of MacIntyre's work. In many places he criticizes a conception of the self that is but a 'free will' which does not identify with the practices in which it takes part. According to MacIntyre this does not offer a good picture of reality. In real life people identify with the practices in which they take part, so they cannot choose to participate in them or leave them at will. This is most obviously the case with practices like motherhood or fatherhood, for mothers and fathers feel these are the roles they play. But in professional practices the same identification mechanism is at work. That explains why it can be a tragedy when a person has to stop working in a practice because of illness or old age. This involves a process of detachment that can be painful, because persons feel that to a large extent the practices are what they do.

MacIntyre shows in many passages that he thinks people identify with their practices. Practices become part of who they are, because practices have allowed individuals to acquire virtues, skills and knowledge that they will keep in any context in which they take part. The moral quest is pushed forwards by the questions that a person encounters in practices, but it is also motivated by the desires that he or she cultivated in those contexts. What the good life is to one person, and what he or she thinks it might be for human beings in general, thus depends very much on the kind of life he or she has led until now. This is what MacIntyre affirms in the following quote:

'What the good life is for a fifth-century Athenian general will not be the same as what it was for a medieval nun or a seventeenth century farmer. But it is not just that different individuals live in different circumstances; it is also that we all approach our own circumstances as bearers of a particular social identity. I am someone's son or daughter, someone else's cousin or uncle; I am a citizen of this or that city, a member of this or that gild or profession; I belong to this clan, that tribe, this nation. Hence what is good for me has to be good for one who inhabits these roles. ${ }^{, 7(p .220)}$

Practices offer a person a social identity, and this identity explains the motivation of people to engage in the moral quest. Engineers are also bearers of such a social identity. When we think in the line of MacIntyre's philosophy, this means we can expect them to be willing to engage in a moral search. This is the case for the engineers in our case-study, but also for other engineers. The fact that they identify with what

q. MacIntyre opposes very much the idea of a life which is fragmented into personal and professional roles. He thinks it is important to see a human life as a whole: that means that the characteristics a person obtains in his or her job will also remain part of who he or she is in other circumstances. (See for example ${ }^{7(p .204-205)}$ ). MacIntyre adopts a narrative view of the unity of a human life: which is a story that is partly told by others who have shaped practices, and partly by the individual. In this short paper we choose not to go into this too far. (See also ${ }^{7 \text { (p.213 \& p..217-218) }}$ ) 
they do as engineers and as parents, friends, neighbors etc... explains why we may expect them to want to reflect on conflicts between the practices in which they engage. If they don't feel motivated to do this, we would feel puzzled about them. We would ask ourselves who they are.

\section{Conclusions}

We wanted to show in what way MacIntyre's moral philosophy could help to form a guideline for thinking about moral responsibility in engineering. The answer is that engineers will have to inspect their interpretation of their responsibility in the light of their view of the good life. This demands that they transcend the standards of evaluation that they make in the concrete practice of their work, and look at whether they can continue to support this evaluation if they consider themselves in another social role, like a parent, neighbor, friend or citizen. All of these roles together constitute a whole human life. If they want to give this life an identity which is their own, they have to make sure the values that are realized in it harmonize with each other. In case of a conflict, agents should rethink the self-evident understanding of their responsibility which is formed in practices, and acquire a new view of it in the light of the good life.

MacIntyre also shows that it can be expected that engineers will be motivated to engage in such a quest. In the case-study this did not seem to be the problem. In the discussion that concluded the study, the engineers seemed to be quite open to reflections about traffic safety; they had just never considered it their responsibility to address traffic safety in their design. However, it was still unclear how they would have to do it. MacIntyre's philosophy shows that they have reason to strive towards harmonization of the standards of evaluation that are part of the practices of which they are participants. Even if they use moral codes to get to a better understanding of what is morally required of them, they will need these practices to interpret the codes.

What would be the result of such a moral evaluation of the case-study of trailer design? This of course depends on the evaluation that the engineers themselves pursue in their concrete lives, but most probably they would conclude that traffic safety is important. Given that engineers are most often also participants in other practices in which they are required to protect themselves or to protect others from getting injured or killed, it can be expected that they will want to protect others also in their role as an engineer.

In our view, MacIntyre's moral philosophy therefore offers an interesting starting point to think about a useful guide for moral reflection. However, a lot of questions remain to be asked, which we will not be able to treat in the scope of this paper. The questions that most ethicists will probably think very urgent are related to MacIntyre's moral epistemology and to the role of external goods. ${ }^{r}$ Morality, we think, forces us to

r. Feminist philosophers are usually very sympathetic to the idea to start reflection on morality in practices. But many are critical of the way in which MacIntyre has developed it. According to them MacIntyre offers too little attention to the way in which power is distributed in the practice. Or with other words: he pays too little attention to the role of the external goods in moral reflection. See for example Frazer and Lacey. ${ }^{14}$ 
think about internal goods as well as external goods. MacIntyre's moral philosophy does not offer a way to deal with the latter, and that is a serious shortcoming of his approach; the more, because the strivings for internal goods cannot be completely separated from the importance of external goods in people's lives, especially when professional practices are considered. However, in the case of trailer design which played the core role in this paper, external goods did not confuse the reflection about morality. The most important confusion at stake was a confusion between moral and internal goods. We think MacIntyre's conceptual framework offers a way to deal with that, which is valuable. But we also think that his approach needs to be improved, in order to be able to deal with different kinds of problems that concern external goods as well. This demands another article.

Acknowledgements: We thank the cooperating engineers and companies. We also wish to thank our colleagues especially Ibo van de Poel, Michiel Brumsen and Anthonie Meijers, who provided us with valuable comments. The anonymous referees have also given us very good feedback and suggestions; we thank them for this.

\section{REFERENCES}

1. www.krone.de.

2. Central Bureau of Statistics and SWOV, www.swov.nl.

3. see www.dodehoek.nl and European Directive 2003/97/EG accessible http://europa.eu.int/eurlex/en/index.html.

4. Davis, M. (1998) Thinking Like an Engineer. Studies in the Ethics of a Profession, Oxford University Press, New York and Oxford.

5. Didier, C. (2000) Engineering ethics at the Catholic university of Lille (France): research and teaching in a European context. European Journal of Engineering Education 25(4): 325-335.

6. See http://www.bouwenmetstaal.nl/.

7. MacIntyre, A.C. (1981), After Virtue. University of Notre Dame Press, Notre Dame.

8. A. van Gorp, Ethical issues in engineering design. This thesis will appear July 2005. The trailer case described in this article is one of four cases from this thesis.

9. See www.cur.nl.

10. www.iee.org.

11. www.abet.org.

12. www.onlineethics.org.

13. www.lockheedmartin.com, www.bp.com, www.whirlpool.com, www.dow.com.

14. Frazer, E. and Lacey, N. (1994) MacIntyre, Feminism and the concept of practice. in: Horton, J. and Mendus S. eds. After MacIntyre; Critical Perspectives on the Work of Alasdair MacIntyre. Polity Press, Cambridge and Oxford.

15. Taylor, Ch. (1994) Justice after virtue in: Horton, J. and Mendus S. eds. After MacIntyre; Critical Perspectives on the Work of Alasdair MacIntyre. Polity Press, Cambridge and Oxford.

16. MacIntyre, A.C.(1994) in: Horton, J. and Mendus S. eds. After MacIntyre; critical perspectives on the work of Alasdair. Polity Press, Cambridge Oxford p.286-290

17. Williams, B. (1985) Ethics and the Limits of Philosophy. Harvard University Press, Cambridge Mass.

18. MacIntyre, A.C. (1990) Three Rival Versions of Moral Enquiry: Encyclopedia, Geneology and Tradition. Duckworth, London.

19. MacIntyre, A.C. (1999) Dependent Rational Animals: Why Human Beings Need the Virtues. Duckworth, London. 